\title{
The Calvary After The Abort Due To Varied Attempts To Treat Rheumatoid Arthirtis By Tnf $\alpha$ Inhibitors And The Final Resolution, Owing To Classic And Orthodox Remedies In An Old Lady Suffering From A Complex Syndrome:A Special Case Report.
}

\author{
Lorenzo Martini \\ Department Of Pharmaceutical Biotechnologies, University Of Siena
}

\begin{abstract}
Scope of this modest case report is to demonstrate that it is not impossible to conciliate the usage of common and orthodox medicaments to combat difficult outcomes deriving from an inconceivable series of syndroms in a single individual.The very importance I want this paper has to herald is that TNF $\alpha$ inhibitors may result perilous and sometimes letal (in peculiar cases) for elder, besides to propose a treatment of that complicated syndrome by the aids of common and orthodox remedies.
\end{abstract}

Keywords: TNF $\alpha$ inhibitors, INR, diabetes mellitus type 1, psoriatic rheumatoid arthritis.

\section{Background}

The Case Report Deals with an Ancient Lady suffering from the Following Syndromes:

$>$ psoriatic rheumatoid arthtritis

$>$ diabetes mellitus type 1

$>$ diverticulitis

and is $84 \mathrm{y}$. old, female and underwent 10 years ago to double knee replacements.

The volunteer (yclept the patient) is not but my mother and for, I have had not to satisfy all the diktats of the Camorra imposed by almost all the Italian Local Ethical Committees, and since I am a doctor (subjected to the Galen's oath), I avail mysef of Sir Thomas Percival's code on medical ethics(1847). Her psoriatic rheumatoid arthritis was diagnosed the very first time when the volunteer was $69 \mathrm{y}$. old. She has been proving 4 kinds of TNF $\alpha$ inhibitors for 12 years, (each of every drug showed a three-yearly efficacy) and this sequence of drugs had destroyed at all her immunological system (she presented always 1000000 Cfus of E. coli in urines; she had loss completely appetite; she grew progressively completely sideropenic and developped a grade 4 cardiac murmur and moreover it must be kept on account that she had never suffered fromany cardiac failure throughout all her life) and when she used to take painkillers (in case of acute attacks of disabling arthritis) the assumption of these drugs forced her to stay at home because of severe risk of diahrroeic episodes.

After this pharmacological Armageddon (euphemistically speaking) she has necessitated one entire year to:

reset her compromised immunological system and stop her severe and recurrent urinary tract infections regain appetite fot all types of aliments present a perfect electrocardiogram with no cardiac murmur of any grade do not suffer from recurrent diarrhoeic episodes, if sometimes she assumed Nsaids.Nevertheless joint pains, due to the rheumatic arthritis, were devastating and the only remedy she could tolerate resulted prednisone (10 mg/pro day), that is known is contraindicated in case of diabetes type 1 , and thus doses of insulins had to be adjusted when required. All this has implied a complex therapeutic carreau, that could never be the same or almost predictable, depending on the quality and quantity of carbohydrates she had ingested during the main meals during the day.

For one entire year this was the therapeutic programme:

$>$ prednisone $5 \mathrm{mg}$ at morning and 5-7 IU of fast-acting insulin

$>$ prednisone $5 \mathrm{mg}$ at 4 p.m. and 6-8 IU of fast-acting insulin

after supper $18 \mathrm{IU}$ of long-acting insulin.

After one year she manifested an important DVT (deep vein thrombosis) at her right leg, with drastic difficulty of deambulation and severe thormoelbolic risk at brain and lungs and her INR was 0.91. Some colleagues of mine (an haematologist and a diabetologist) have supposed that chronic usage of prednisone involves the formation of clots that drives to deep vein thrombosis,DVT $(1,2)$ and even knee replacement can constitute a serious hazard for thromboembolic episodes in lower imbs.(3) and moreover peaks of hyperglycaemia (even if sporadic) when exceed $350 \mathrm{mg} / \mathrm{dL}$ may drive the same to thromboembolic episodes at lower extremities $(4,5)$

The great concern began so to come up with the possibility of coordinating the administration of Painkillers (avoiding absolutely corticosteroids)

$>$ The insulines

$>$ The anticoagulants.

It must be stressed that the patient, when she was under TNF $\alpha$ inhibitors could not take Nsaids, because of the severe diarrhoeic flows, but now, after one year she has stopped with the aforementioned drugs, she does not present the same problem and so the choice of antinflammatory medicaments is fortunately broad:

$>$ ketoprofene

$>$ diclofenac

$>$ sulindac 


\section{$>$ sodium naproxene}

$>$ indomethacin at moderate or high dosages to alternate to acetaminophen.

Paying attention that some of these Nsaids can alterate the glycemic value, one or two IU of fast-acting insulin had to be added (in the morning, at lunch time and at 4 o'clock in the afternoon) to the regular dosage.

\section{Materials and methods}

And so the schedule of painkillers and insulines became the following:

at morning: acetaminophen $(1 \mathrm{~g})$ and $4 \mathrm{IU}$ of fast acting insulin (depending on the carbohydrates assumed at morning breakfast or no IU of insulin)

at lunch time: diclofenac $(100 \mathrm{mg})$ or indomethacin $(50 \mathrm{mg})$ and $8 \mathrm{IU}$ of fast-acting insulin

at supper time: acetaminophen $(1 \mathrm{~g})$ and 16 or $18 \mathrm{IU}$ of long-acting insulin, depending on carbohydrates assumed by diet.

As far as anticoagulants, in order to reach a INR comprised between 2 and 3, the schedule has been the following:

first day: coumadin $(5 \mathrm{mg})$ at 4 p.m. and mesoglycane $(50 \mathrm{mg})$ at supper time

from the second to the fourth day: coumadin $(5 \mathrm{mg})$ at 4 p.m. and coumadin $2.5 \mathrm{mg}$ at supper time.

After the fourth day the INR reached the value 1.72 , I repute this value quite satisfying.

according to the protocol of the initiation of warfarin, one may behold in Table I:

TableI: Warfarin Initiation Dosing Protocol (Week 1) with INR Goal 2-3

\begin{tabular}{|l|l|l|}
\hline Day therapy & INR value & Total day dose \\
\hline Day 1 & & $5 \mathrm{mg}$ \\
\hline In 2-3 days after initiation & $<1.5$ & $5-7.5 \mathrm{mg} / \mathrm{die}$ \\
& $1.5-1.9$ & $2.5-5 \mathrm{mg} / \mathrm{die}$ \\
& $2.0-2.5$ & $2.5 \mathrm{mg} / \mathrm{die}$ \\
& $<2.5$ & Need for a re-check \\
\hline After 4th day & $<1.5$ & $7.5 / 10 \mathrm{mg} /$ die \\
& $1.5-1.9$ & $5-10 /$ die \\
& $2.0-3.0$ & $2.5-5 /$ die \\
& $>3$ & Need for a re-check \\
\hline
\end{tabular}

in order to achieve the INR I had foretold.

\section{Results}

The craved result is achieved, so I have fain prosecuted with the suggested doses by the Protocol (6),administering coumadin $2.5 \mathrm{mg} / \mathrm{die}$ until the 8th day when I have the test of INR effectuated. Finally, the INR value was 2.2 (for this complex clinical picture, the range of INR 2-3 is more than favorable). Concomitantly, some A.A. (6), assert that corticosteroids may increase the INR value after some days in patients taking coumadin and the augmentation of the value is observable after $6.7+/-3.3$ days from the first assumption of corticosteroids. So at 9 th day the volunteer began to take again prednisone at the same prior dosages and after other 10 days the INR value was 2.8 . The therapy could remain the same for long time and aught of irreparable occurred.

\section{Discussions}

Inr 2.8 avoids risks of pulmonary embolism and cerebral venous thrombosis as well, as I feared at the first occurrence of symptoms of DVT in the volunteer. This case is very particular, but I deem the clinical trial and the results can be useful for everybody (especially women over 60 suffering from DVT and rheumatic arthritis evoked by diverse causes, instead of diabetes mellitus type 1).

\section{Conclusions}

The remission after 12 years of assumption of TNF $\alpha$ inhibitors has been dramatic and those drugs should be baished, especially in Italy where Camorra and Mafia of the Hospitals reigns as Souvereign.

\section{References}

[1] Otsuka F, Amano T, Uchida H, Ogura T, Makino H.;A case of idiopathic deep vein thrombosis improved with glucocorticoid therapy.Haematologia (Budap). 1999;29(4):305-1

[2] Johannesdottir SA, Horváth-Puhó E, Dekkers OM, Cannegieter SC, Jørgensen JO, Ehrenstein V, Vandenbroucke JP, Pedersen L, Sørensen HT.:2013; Use of glucocorticoids and risk of venous thromboembolism: a nationwide population-based case-control study;2013.JAMA Intern Med.13;173(9):743-52

[3] Ruban P, Yeo SJ, Seow KH, Tan SK, Ng SC.; Deep vein thrombosis after total knee replacement 2000;Ann Acad Med Singapore,;29(4):428-33.

[4] Yunjian Zhang1, Yawei Shi1, Runyi Ye1, Nan Shao1, Fushun Pan2, Ying Lin1, Shenming Wang1 ; Diabetes mellitus-associated hyperglycemia is a risk factor for recurring deep vein thrombosis and post-thrombotic syndrome-a cohort study;2016: Int J Clin Exp Med 2016;9(9):17739-17749

[5] Hermanides et al:Venous thrombosis is associated with hyperglycemia at diagnosis: a case-control study:2009; Journal of Thrombosis and Haemostasis, 20 may 2009.

[6] http://www.uwhealth.org/files/uwhealth/docs/pdf3/Warfarin_Dosing_Protocol.pdf 